\title{
Increased incidence of cancer in first degree relatives of women with double primary carcinomas of the breast and colon
}

\author{
William D Foulkes, Natalie Bolduc, Deborah Lambert, Ophira Ginsburg, \\ Leonard Olien, David W Yandell, Patricia N Tonin, Steven A Narod
}

\begin{abstract}
Breast and colon cancer are among the most common cancers in the developed world. Several epidemiological studies suggest that the occurrence of one of these two cancers in a woman may predispose to the development of the other. The occurrence of both forms of cancer in the same woman may be because of chance or common susceptibility. In order to determine how frequently double primary cancers have a hereditary basis, we conducted a registry based study at a single Montreal hospital. Cancer rates in first degree relatives of patients with multiple primaries were compared with provincial age standardised incidence rates and relative risks (RRs) were estimated. In first degree relatives under 45 there was a total of 15 cancers observed, compared with $3.70 \mathrm{ex}-$ pected, giving an RR of $4 \cdot 05$ (95\% CI: 2.276.68). The RR for colon cancer was significantly increased among male relatives. For relatives less than $\mathbf{4 5}$ years old at diagnosis, the $\mathbf{R R}$ for colon cancer was 66.7 (95\% CI: 13.8-195) (three cases observed, 0.045 expected). For all ages the RR was 5.02 (95\% CI: $2 \cdot 04-10 \cdot 5)$. The RR for breast cancer was 5.92 (95\% CI: 1.9113.8) for female relatives under 45 (five cases observed, 0.845 expected) and 2.14 (95\% CI: $1 \cdot 07-3 \cdot 83)$ for breast cancer at any age. These results suggest that there may be genes that predispose to both breast and colon cancer in certain people. ( 7 Med Genet 1996;33:534-539)
\end{abstract}

Key words: breast cancer; colon cancer; family history.

Multiple primary cancers are characteristic of hereditary cancer syndromes. When these double primaries are observed more frequently than would be expected by chance, it is reasonable to look for a common genetic origin. Several studies have shown an increased incidence of breast cancer following colon cancer and vice versa. ${ }^{12}$ However, the overall risk increase is modest. In a combined analysis of seven cohort studies, there was a slightly in- creased relative risk of a second primary of the breast after a primary colon cancer and vice versa $(1 \cdot 10,95 \% \mathrm{CI}: 1 \cdot 03-1 \cdot 17 ; 1 \cdot 15,95 \%$ CI: $0 \cdot 99-1 \cdot 31$, respectively). ${ }^{3}$ Breast and colon cancer have several risk factors in common. For example, increased consumption of dietary fat has been reported to increase risk of both diseases. ${ }^{4}$ If multiple primary cancers are primarily the result of hereditary factors, we would expect to see an increased cancer risk in relatives, and this increase should be greater than that associated with each site alone. To test this hypothesis we identified cases of breast and colon cancer occurring in the same woman from the tumour registry of the Royal Victoria Hospital, Montreal, Quebec. A detailed family history of cancer was obtained from each case. We compared the observed rates of cancer in the relatives of cases of double primary cancer of the breast and colon with expected rates for the Quebec and Canadian populations.

\section{Materials and methods}

ASCERTAINMENT OF PROBANDS

The tumour registry of the Royal Victoria Hospital contains information on patients who are diagnosed with all types of cancer. The reporting of cancer cases to the Tumour Registry by the Department of Pathology is obligatory. All entries for the years 1950-92 were reviewed; in 63 cases cancer of the female breast was later followed by cancer of the colon (or vice versa). All 63 patients had been under the care of surgeons in the Royal Victoria Hospital. The patient records of affected women were studied and the relevant clinical information was extracted. The diagnosis in the proband was confirmed by examination of the patient's medical records and pathology report for 61 of the 63 cases. In no case was there disagreement between the registry details and the information provided by patient charts or by the proband herself. As far as is known, no women were referred to this hospital because of family history. No attempt was made to verify the diagnosis of cancer in first degree relatives. However, the diagnosis of cancer reported in first degree relatives is very likely to be accurate. ${ }^{56}$ No systematic attempt was made 
Table 1 Relative risk of cancer in first degree relatives associated with a double primary of the breast and colon in the female proband

\begin{tabular}{llccc}
\hline Site or type of cancer* & $\begin{array}{l}\text { Age group } \\
(y)\end{array}$ & Observed & Expected & $\begin{array}{c}\text { Relative risk }(95 \% \\
\text { confidence intervals) }\end{array}$ \\
\hline All sites & $<45$ & 15 & $3 \cdot 70$ & $4 \cdot 05(2 \cdot 27-6 \cdot 68)$ \\
& $<55$ & 22 & $8 \cdot 53$ & $2 \cdot 58(1 \cdot 61-3 \cdot 90)$ \\
Breast & All ages & 43 & $32 \cdot 3$ & $1 \cdot 33(0 \cdot 96-1 \cdot 79)$ \\
& $<45$ & 5 & $0 \cdot 845$ & $5 \cdot 92(1 \cdot 91-13 \cdot 8)$ \\
Colon & $<55$ & 8 & $2 \cdot 02$ & $3 \cdot 95(1 \cdot 70-7 \cdot 79)$ \\
& All ages & 11 & $5 \cdot 14$ & $2 \cdot 14(1 \cdot 07-3 \cdot 83)$ \\
Bladder & $<45$ & 3 & $0 \cdot 110$ & $27 \cdot 3(5 \cdot 48-79 \cdot 6)$ \\
& $<55$ & 4 & $0 \cdot 462$ & $8 \cdot 66(2 \cdot 33-22 \cdot 2)$ \\
Malignant melanoma & All ages & 9 & $2 \cdot 99$ & $3 \cdot 01(1 \cdot 36-5 \cdot 67)$ \\
& $<45$ & 0 & 0.070 & - \\
& $<55$ & 0 & 0.235 & - \\
& All ages & 2 & $1 \cdot 63$ & $1 \cdot 23(0 \cdot 14-4 \cdot 44)$ \\
& $<45$ & 1 & 0.348 & $2 \cdot 88(0 \cdot 04-16 \cdot 0)$ \\
& $<55$ & 1 & 0.550 & $1 \cdot 82(0 \cdot 02-10 \cdot 1)$ \\
& All ages & 3 & 0.956 & $3 \cdot 14(0 \cdot 63-9 \cdot 17)$ \\
\hline
\end{tabular}

* Sites refer to any cancer site seen more than once in the 26 pedigrees.

Table 2 Relative risk of cancer in female first degree relatives associated with a double primary of the breast and colon in the female proband

\begin{tabular}{|c|c|c|c|c|}
\hline Site or type of cancer & $\begin{array}{l}\text { Age group } \\
\text { (y) }\end{array}$ & Observed & Expected & $\begin{array}{l}\text { Relative risk (95\% } \\
\text { confidence intervals) }\end{array}$ \\
\hline All sites & $\begin{array}{l}<45 \\
<55\end{array}$ & $\begin{array}{l}11 \\
16 \\
26\end{array}$ & $\begin{array}{r}2.43 \\
5 \cdot 29 \\
16 \cdot 7\end{array}$ & $\begin{array}{l}4.52(2.25-8.09) \\
3.02(1.73-4.91) \\
1.56\end{array}$ \\
\hline Breast & $\begin{array}{l}<45 \\
<55 \\
\text { All ages }\end{array}$ & $\begin{array}{r}20 \\
5 \\
8 \\
11\end{array}$ & $\begin{array}{l}0 \cdot 84 \\
2 \cdot 02 \\
5 \cdot 14\end{array}$ & $\begin{array}{l}5.92(1.91-13.8) \\
3.95(1.70-7.79) \\
2.14(1.07-3.84)\end{array}$ \\
\hline Colon & $\begin{array}{l}<45 \\
<55 \\
\text { All ages }\end{array}$ & $\begin{array}{l}0 \\
1 \\
2\end{array}$ & $\begin{array}{l}0.065 \\
0.254 \\
1.64\end{array}$ & $\begin{array}{l}3.93(0.05-21 \cdot 9) \\
1.22(0.14-4.41)\end{array}$ \\
\hline Malignant melanoma & $\begin{array}{l}<45 \\
<55 \\
\text { All ages }\end{array}$ & $\begin{array}{l}1 \\
1 \\
2\end{array}$ & $\begin{array}{l}0.215 \\
0.330 \\
0.527\end{array}$ & $\begin{array}{l}4.66(0.06-25.92) \\
3.02(0.04-16.83) \\
3.79(0.43-13.7)\end{array}$ \\
\hline
\end{tabular}

to record information on second degree relatives, as this information is substantially less reliable than that gathered from first degree relatives. ${ }^{56}$

\section{FAMILY HISTORY}

Forty of the 61 probands had died. It was possible to contact the proband or the proband's next of kin in 26 cases. The interview was conducted with the proband in 14 cases and with a family member in the remaining 12 cases. A detailed family history was taken from these 26 people, representing $41 \%$ of the original probands identified as described above. Six families were of French-Canadian origin, six were Jewish, 10 were originally from the UK, and four were of mixed European descent. The interviews were conducted in person or by telephone. The family history included age of death, age of diagnosis of cancer, and site (and if possible histological type) of cancer in all first degree relatives of the proband. No patient or next of kin refused to take part in the study.

\section{STATISTICAL ANALYSIS}

The observed number of cases in the first degree relatives was determined by review of family pedigrees. The expected number of cases for each cancer was derived from the product of the person years and the provincial cancer rate for each age range, divided by 100000 . People were considered to be at risk of other cancer until death or age in 1994. The expected number of cases was calculated for each of the age ranges selected. The relative risk (RR) of cancer in a first degree relative associated with a family history of double primary cancer of the breast and colon was calculated by comparing observed to expected figures using Quebec provincial health statistics. Quebec figures for melanoma were not available and Canadian health statistics were used. The confidence intervals (CIs) were calculated assuming a Poisson distribution, $\mathrm{CI}=\mathrm{O}_{\mathrm{L}} / \mathrm{E}-\mathrm{O}_{\mathrm{U}} / \mathrm{E}$, where $\mathrm{O}_{\mathrm{L}}$ is the lower bound and $\mathrm{O}_{\mathrm{U}}$ is upper bound. The formula used is very sensitive to the number of observations and its use is recommended when comparing observed incidence rates. ${ }^{7}$

Lower bound

$$
\mathrm{O}_{\mathrm{L}}=\mathrm{O} *\left(\left[1-\left(\frac{1}{9 * \mathrm{O}}\right)\right]-\left[\frac{\mathrm{Z}_{x / 2}}{3 * \sqrt{\mathrm{O}}}\right]\right)^{3}
$$

Upper bound

$$
\begin{aligned}
\mathrm{O}_{\mathrm{U}}= & (\mathrm{O}+1) *\left(\left(1-\left[\frac{1}{9 *(\mathrm{O}+1)}\right]\right)\right. \\
& \left.+\left[\frac{\mathrm{Z}_{x / 2}}{3 * \sqrt{(\mathrm{O}+1)}}\right]\right)^{3}
\end{aligned}
$$

\section{Results}

There were 26 probands with two primary cancers. In 14 cases the breast cancer was diagnosed first (at a mean age of 63.0 years, range 29-88), and in 12 colon cancer was diagnosed first (at a mean age of 64.9 years, range 37-88). Four probands were diagnosed with both breast and colon cancer at less than 50 years of age. The mean interval between diagnosis of the two cancers was 8.27 years (range 1-38 years, median five years). The 26 probands had 193 first degree relatives (an average of 7.4 first degree relatives). There were 4685 man years and 6211 woman years of exposure until death or current age. A total of 43 cancers were reported in the 193 relatives $(22 \cdot 3 \%)$.

Fifteen first degree relatives had cancer diagnosed at the age of 45 years or earlier. The expected number is $3 \cdot 70$, giving a relative risk (RR) (observed/expected ratio) of cancer at any site associated with a double primary in the proband of 4.05 (95\% confidence interval (CI): $2 \cdot 27-6 \cdot 68)$. For cancer at all ages, the observed figure was not significantly greater than that expected (table 1).

Eleven of 110 female first degree relatives had breast cancer (age range 31-70 years). There were five woman who had breast cancer diagnosed at less than 45 years of age. As only 0.84 cases are expected, this results in an RR for breast cancer of 5.92 (95\% CI: 1.91-13.81) (table 2). If both the relative and the proband were diagnosed with breast cancer at less than 45 years of age then the RR was 26.9 (95\% CI: 5.41-77-3). However, all three cases in this category came from one family (see below). 
Table 3 Relative risk of cancer in male first degree relatives associated with a double primary of the breast and colon in the female proband

\begin{tabular}{llccc}
\hline Site or type of cancer & $\begin{array}{l}\text { Age group } \\
(y)\end{array}$ & Observed & Expected & $\begin{array}{l}\text { Relative risk (95\% } \\
\text { confidence intervals) }\end{array}$ \\
\hline All sites & $<45$ & 4 & $1 \cdot 27$ & $3 \cdot 15(0 \cdot 85-8 \cdot 07)$ \\
& $<55$ & 6 & $3 \cdot 25$ & $1 \cdot 85(0 \cdot 68-4 \cdot 02)$ \\
Breast & All ages & 17 & 15.6 & $1 \cdot 09(0 \cdot 64-1 \cdot 75)$ \\
& $<45$ & 3 & $0 \cdot 045$ & $66 \cdot 7(13 \cdot 4-195)$ \\
Colon & $<55$ & 3 & $0 \cdot 208$ & $14 \cdot 4(2 \cdot 90-42 \cdot 2)$ \\
& All ages & 7 & 1.37 & $5 \cdot 09(2 \cdot 04-10 \cdot 5)$ \\
Malignant melanoma & $<45$ & 0 & $0 \cdot 052$ & - \\
& $<55$ & 0 & $0 \cdot 168$ & - \\
& All ages & 2 & $1 \cdot 17$ & $1 \cdot 71(0 \cdot 19-6 \cdot 18)$ \\
& $<45$ & 0 & $0 \cdot 133$ & - \\
& $<55$ & 0 & $0 \cdot 220$ & - \\
& All ages & 1 & $0 \cdot 428$ & $2 \cdot 33(0 \cdot 93-13 \cdot 0)$ \\
\hline
\end{tabular}

Colon cancer diagnosed at less than 45 years old was seen in three first degree relatives, whereas $0 \cdot 11$ were expected, giving an $R R$ of $27 \cdot 26$ (95\% CI: 5·45-79.64). The risk remained increased for colon cancer at any age: nine cases were observed and 3.01 were expected. The RR was significantly increased for men only (tables 1-3). Seven of 93 male first degree relatives had colon cancer (age range 30-73 years), including three men who had colon cancer diagnosed in their thirties (ages 30,33 , and 34). This results in an RR of 66.67 (95\% CI: $13 \cdot 4-19 \cdot 5)$. Two of the three cases of colon cancer seen in men under 45 were accounted for by relatives of three probands who themselves had been diagnosed with colon cancer at less than 45 years of age. This latter group resulted in an $\mathrm{RR}$ of $432(95 \% \mathrm{CI}$ : 48.5-1560). As for breast cancer, these two cases of very early onset colon cancer came from one family (figure).

The only other cancers that were seen more than once were melanoma and bladder cancer. There was no significantly increased frequency of these cancers (tables 1-3).

Much of the excess colon and breast cancer risk could be attributed to one pedigree (figure). This pedigree contains three female first degree relatives with breast cancer, diagnosed at ages 31 to 38 , and two male first degree relatives with colon cancer, diagnosed at the ages of 33 and 34. Because of the possibility that this one large family might account for all the increased risk seen, the person years were recalculated and the data were analysed after excluding this family. For both sexes, and cancer at all sites in those under 45 , there was a fall in the RR from $4 \cdot 02$ to $2 \cdot 82$, but this remained significant (95\% CI: $1 \cdot 35-5 \cdot 20)$. The values for other age groups did not change appreciably. In women, the $R R$ for cancer at any site is still significantly raised: 3.42 (95\% CI: $1 \cdot 47-6 \cdot 73)$ for those less than 45 years old at time of diagnosis, and 2.54 (95\% CI: 1.35-4.34) for those under 55 years old. The RR for colon cancer in males at all ages falls to 3.67 but remains significant ( $95 \%$ CI: $1 \cdot 18-8 \cdot 57)$. The RR associated with breast cancer in the younger age groups also falls $(2 \cdot 46,95 \%$ CI: $0 \cdot 28-8 \cdot 87)$.

This one large family has a clear excess of both young onset breast and colorectal cancer. Therefore this pedigree has been studied in more detail. Pathological confirmation of all diagnoses of cancer was obtained. The possibility of a germline mutation in several of the known cancer susceptibility genes, predisposing to breast or colon cancer, was studied by linkage and mutation analysis. In one affected subject, mutations were sought in exons 2-11 of TP53 with single strand conformation analysis, using a standard protocol. ${ }^{8}$ No mutation was found. In addition, markers adjacent to or within the BRCA1, BRCA2, hMLH1, and $\mathrm{hMSH} 2$ loci were assessed by linkage analysis in this family using MLINK in the LINKAGE program. The results show that when it is assumed that a single locus is responsible for both breast and colon cancer, the highest positive lod score is +0.096 with D2S119 near hMSH2, but in no case could a common haplotype be found in all affected subjects.

It is possible that an allele of BRCA1 is cosegregating with the breast cancer cases in this family, as excluding the colon cancer cases resulted in an increase in the lod score from -0.17 to +0.16 using D17S855. Similarly, the linkage results with $\mathrm{D} 3 \mathrm{~S} 1076$, adjacent to hMLH 1 on chromosome $3 \mathrm{p}$, suggest a mutation in this gene may be responsible for the colon cancer in this family, as excluding the breast cancer cases resulted in the lod score increasing from -0.39 to $+0 \cdot 18$. These linkage results are based on marker studies of only three affected persons (figure), and cannot be conclusive. It also possible that a novel gene could be linked to the cancers in this family.

\section{Discussion}

Reports of possible associations of breast and colorectal cancer within families go back at least as far as $1904 .^{9}$ A number of cohort and case control studies have examined the familial relationship between breast and colon cancer, but the results are conflicting, with some studies showing no relationship ${ }^{10-13}$ and others suggesting a moderate positive association. ${ }^{14-17}$ No studies have attempted specifically to study the family history of double primary cancers of the breast and colon, but others have shown that one indicator of increased likelihood of genetic factors playing an important role in a malignant disease is the incidence of two distinct primary tumours in one person. ${ }^{18}$ However, as both cancers are common in the developed world, it is possible that two cancers in the same woman could be seen by chance, and would therefore not be expected to be associated with a family history of cancer. This study has shown that in families ascertained through a woman with a double primary cancer of the breast and colon, there were significantly increased risks in that family for developing early onset breast cancer and colon cancer. Risks were also significantly increased for any cancer in younger women. This suggests that chance is not a likely explanation for these data.

When the data are reanalysed using different age group categories, it can be seen that the main excess of cancer occurs in those under 45 at diagnosis ( $R R 4.05$, table 1 ), particularly if the proband had both breast and colon cancer diagnosed at less than 50 years of age (RR for all cancers, $10 \cdot 7,95 \%$ CI: 3.9-23.3). Breast 
cancer in female relatives and colon cancer in male relatives account for most of the increased risk. In the age group 45 to 54 , there are too few observed cases to generate significant data (point estimate of RR: 1.45), but in the 55 to 74 age group, results similar to those seen for all ages were obtained (RR of any cancer, $1 \cdot 22$, 95\% CI: 0.75-1.89; compare with table 1 ). Therefore, not surprisingly, there is a significant deficit of cancer in the $75+$ age group (all cancers, RR $0 \cdot 14,95 \%$ CI: $0 \cdot 0018-0 \cdot 75$ ).

By comparing our results with those obtained in prospective cohort studies, it can be seen that risks for colon cancer in men and breast cancer in younger women associated with a family history of a double primary of these cancers is greater than the risk associated with a family history of each of these cancers alone. From two continuing cohort studies, 119116 US health workers provided details of family history of cancer. ${ }^{19}$ Using a person years approach, based on 73 cases, it was estimated that the RR of colorectal cancer associated with a family history of this cancer was 1.72 (95\% CI: $1 \cdot 33-2 \cdot 20)$. For the five cases diagnosed at under 45 , the RR was $5 \cdot 37$ (95\% CI: $1.98-$ 17.4). In our series, the corresponding risks were $3.01(95 \% \mathrm{CI}: 1 \cdot 36-5 \cdot 67)$ and $27 \cdot 3(95 \%$
CI: 5.48-79.6), based on nine and three cases, respectively. For breast cancer, a comparison can be made with a component of the study group discussed above. In the Nurses' Health Study, of 117988 women followed up from 1976 to 1988 there were 2389 incident cases of breast cancer, among whom 220 had a mother with breast cancer. ${ }^{20}$ The age adjusted RR associated with a maternal history of breast cancer was $1.8(95 \% \mathrm{CI}: 1.5-2.0)$ and if the mother was diagnosed before the age of 40 , the RR was $2 \cdot 1(95 \%$ CI: $1 \cdot 6-2 \cdot 8)$. Risks associated with sisters with breast cancer were similar. We showed RRs of 5.92 (95\% CI: 1.91-13.8) for those under 45 and $2 \cdot 14$ (95\% CI: $1 \cdot 07-3 \cdot 84)$ for breast cancer at any age. Thus our data are consistent with the hypothesis that the risk of either cancer in relatives of probands with double primaries is greater than that associated with either one cancer alone.

Shared environmental or hormonal factors could account for the increased RRs seen in the relatives. A number of studies have suggested that dietary risk factors, such as saturated fat intake, may be common to both diseases. ${ }^{2}$ Similarly, reproductive and hormonal factors may contribute to the incidence of colorectal cancer. ${ }^{21}$ Prospective studies have shown

Family 111

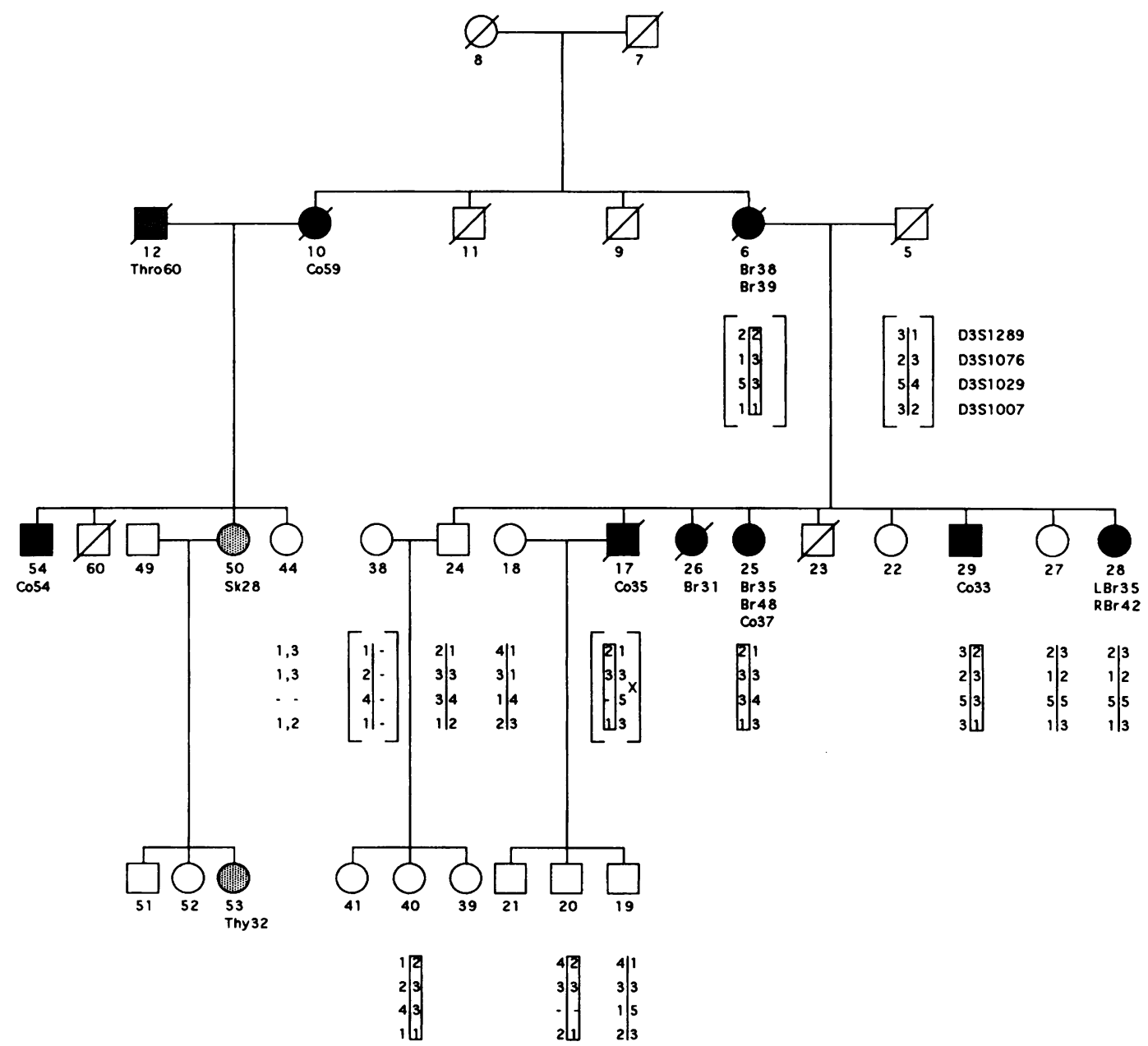

Family 111. The common haplotype seen for the four chromosome 3 markers used is boxed. Boxes in square brackets are inferred haplotypes. The $X$ denotes an inferred recombination. The numbers immediately under the symbols are individual numbers. The filled in symbols denote affected persons. $B r=b r e a s t$ cancer; $C o=$ colon cancer; $S k=$ skin cancer; Thy $=$ thyroid cancer; Thro = throat cancer. The number next to the cancer site refers to the age at diagnosis of cancer. 
that oestrogen replacement therapy is protective against colorectal cancer. ${ }^{22}$ There may be an increased risk of colorectal cancer associated with adjuvant tamoxifen therapy for early stage breast cancer. ${ }^{23}$ There is a notable lack of excess of colon cancer in the female relatives of the double primary cases in this study. It is not clear why this is the case, but chance and shared (protecting) hormonal factors may be important.

The adenoma-carcinoma sequence is a plausible explanation for the origin of colorectal carcinomas. ${ }^{24}$ We do not have data on the prevalence of colonic polyps in our pedigrees, but previous case control studies have addressed this issue. From the most thorough study, it appears that colonic adenomas are not more frequent in breast cancer patients than in unaffected controls. ${ }^{25}$

Several inherited cancer syndromes include colon carcinoma. The two major types are familial adenomatous polyposis and hereditary non-polyposis colorectal cancer (HNPCC). Neither of these syndromes is clearly associated with a significantly increased risk of breast carcinoma. ${ }^{2627}$ Hereditary breast cancer is principally attributable to mutations in two genes, BRCA1 and BRCA2. There appears to be an increased risk of colorectal cancer in pedigrees containing BRCA1 mutations, ${ }^{28}$ but this requires further investigation. None of the 26 probands in our series appeared to be members of breast-ovarian cancer pedigrees. A case of multiple primary cancer of the breast and colon in a male who has inherited the disease related haplotype at BRCA2 has also been reported, ${ }^{29}$ but there was no excess of breast cancer in men with colorectal cancer in a SEER based study. ${ }^{30}$

The gene TP53 is mutated in many families with the Li-Fraumeni syndrome, but is only rarely found to be mutated in multiple cancer families that do not fulfil the restricted or extended criteria of Li-Fraumeni syndrome. ${ }^{31}$ While the presence of early onset breast cancer would support the possibility of mutations in this gene, the absence of paediatric cancers and the presence of multiple cases of colon cancer suggest that mutations in TP53 would not be expected in family 111 . The absence of mutation in exons 2-11 of TP53 fulfils this expectation. On the basis of the haplotype and linkage results with markers adjacent to the BRCA2 and hMSH2 loci, these genes do not appear to be causally implicated in the cancers in this family. The possibility that a mutant allele of one gene (BRCA1) is segregating with the breast cancer in this family, and another gene (hMLH1) is associated with the colon cancer is supported by haplotype results (figure, and data not shown), but must remain conjectural because of the small number of typed subjects.

The possibility that breast and colorectal carcinoma in a family share underlying aetiological factors is reliably shown by the large population based study of Goldgar et al. ${ }^{17}$ Using the Utah population database, they showed that first degree relatives of probands with colon cancer were at an increased risk of breast cancer (early onset colon cancer: RR $1.40,95 \%$ CI,
$1 \cdot 1-1 \cdot 8$; colon cancer at any age: $\operatorname{RR} 1 \cdot 23$, $95 \% \mathrm{CI}, 1 \cdot 1-1 \cdot 4)$. The reverse association was also positive, first degree relatives of breast cancer probands having increased risks of colon cancer (early onset breast cancer, RR 1.72, 95\% CI: $1 \cdot 3-2 \cdot 2$; breast cancer at any age, RR $1 \cdot 35 ; 95 \% \mathrm{CI}: 1 \cdot 2-1 \cdot 5)$. Although the risks appear to be smaller than those found in our study, Goldgar $e t ~ a l^{17}$ studied relatives of cases with single primaries, whereas we studied relatives of cases of double primaries, where genetic effects are thought to be more pronounced.

This study has shown that first degree relatives of women with double primary cancers of the breast and colon are at increased risk of breast and colon cancer. Environmental, hormonal, and genetic factors are all likely to be important. The relative contribution of genetic factors to the cancers in these families may be greater than is currently appreciated.

We thank the probands and their families for cooperation, JeanSebastien Brunet for statistical advice, and the two referees for their comments. The study was supported in part by the Canadian Genetic Diseases Network.

1 Teppo L, Pukkala E, Saxen E. Multiple cancer - an epidemiologic exercise in Finland. 7 Natl Cancer Inst 1985; 75:207-17.

2 Enbland P, Adami HO, Glimelius B, Krusemo U, Pahlman L. The risk of subsequent primary malignant diseases after cancers of the colon and rectum. A nationwide cohort study. Cancer 1990;65:2091-100.

3 Eisen GM, Sandler, RS. Are women with breast cancer more likely to develop colorectal cancer? $\mathcal{f}$ Clin Gastroenterol 1994;19:57-63.

4 Willett W. The search for the causes of breast and colon cancer. Nature 1989;338:389-94.

5 Love RR, Evans AM, Josten DM. The accuracy of patient reports of a family history of cancer. $\mathcal{F}$ Chron Dis 1985; 38:289-93.

6 Aitken J, Bain C, Ward M, Siskind V, MacLennan R. How accurate is self-reported family history of colorectal cancer? Am $\mathcal{f}$ Epidemiol 1985;141:863-71.

7 Breslow NE, Day NE. The design and analysis of cohor studies. Statistical methods in cancer research. Vol II. Lyon: IARC, 1987.

8 Toguchida J, Yamaguchi T, Ritchie B, et al. Mutation spectrum of the p 53 gene in bone and soft tissue sarcomas. spectrum of the p53 gene in bond
Cancer $1992 ; 52: 6194-9$.

9 Watkins DJG. A family tree. BMF 1904;i: 190

10 Woolf CM. A genetic study of carcinoma of the large intestine. Am f Hum Genet 1985;10:42-7.

11 Ponz de Leon M, Sassatelli R, Sacchetti C, Zanghieri G, Salmati A, Roncucci L. Familial aggregation of tumors in the three-year experience of a population-based colorectal cancer registry. Cancer Res 1989;49:4344-8.

12 Stephenson BM, Finan PJ, Gascoyne J, Garbett F, Murday VA, Bishop DT. Frequency of familial colorectal cancer. Br F Surg 1991;78:1162-6.

13 St John DJB, McDermott FT, Hopper JL, Debney EA Johnson WR, Hughes ESR. Cancer risk in relatives of patients with common colorectal cancer. Ann Intern Med 1993;118:785-90.

14 Andrieu N, Clavel F, Archier A, et al. Association between breast cancer and family malignancies. Eur $\mathcal{F}$ Cancer 1991 ; 27:244-8.

15 Phipps RF, Perry PM. Familial breast cancer and the association with colonic carcinoma. Eur f Surg Oncol 1989;15: ation with

16 Nelson CL, Sellers TA, Rich SS, Potter JD, McGovern PG, Kushi LH. Familial clustering of colon, breast, uterine, and ovarian cancers as assessed by family history. Genet Epidemiol 1993;10:235-44.

17 Goldgar DE, Easton DF, Cannon-Albright LA, Skolnick MH. Systematic population-based assessment of cancer risk in first-degree relatives of cancer probands. $\mathcal{F}$ Natl Cancer Inst 1994;86:1600-8.

18 Shah S, Evans DGR, Blair V, Burnell LD, Birch JM. Assessment of relative risk of second primary tumors after ovarian cancer and the usefulness of double primary cases as a source of material for genetic studies with a cance registry. Cancer 1993;72:819-27.

19 Fuchs CS, Giocannucci EL, Colditz GA, Hunter DJ, Speizer FE, Willett WC. A prospective study of family history and the risk of colorectal cancer. $N$ Engl $\mathcal{f}$ Med 1994;331: 1669-74.

20 Colditz GA, Willett WC, Hunter DJ, et al. Family history, age, and risk of breast cancer. Prospective data from age, and risk of breast cancer. Prospective da
Nurses' Health Study. $¥ A M A$ 1993;270:2925-6.

21 Potter JD, McMichael AJ. Large bowel cancer in women in relation to reproductive and hormonal factors: a casecontrol study. $\mathcal{F}$ Natl Cancer Inst 1983;71:703-9. 
22 Chute CG, Willett WC, Colditz GA, Stampfer MJ, Rosner B, Speizer FE. A prospective study of reproductive history and exogenous estrogens on the risk of colorectal cancer in women. Epidemiology 1991;2:201-7.

23 Rutqvist LE, Johansson $H$, Signomklao T, Johansson U, Fornander T, Wilking N. Adjuvant tamoxifen therapy for early stage breast cancer and second primary malignancies. early stage breast cancer and second

24 Muto T, Bussey HJR, Morson BC. The evolution of cancer of the colon and rectum. Cancer 1975;36:2251-70.

25 Muray TI Neurectum. Cancer 1975;36:2251-70. KA, Treat MR. Relationship between breast cancer and KA, Treat MR. Relationship between breast cancer and
colorectal adenomatous polyps. A case-control study. Cancolorectal adenomato

26 Jagelman DG. Extracolonic manifestations of familial polyposis coli. Semin Surg Oncol 1987;3:88-91.
27 Watson P, Lynch HT. Extracolonic cancer in hereditary .

28 Ford D, Easton DF, Bishop DT, Narod SA, Goldgar DE, and the Breast Cancer Linkage Consortium. Risks of cancer in BRCA1-mutation carriers. Lancet 1994;343:692-5.

29 Tonin P, Ghadirian P, Phelan C, et al. Case report: a large multisite cancer family is linked to BRCA2. $\mathfrak{F}$ Med Genet 1995;32:982-4.

30 Neugut AI, Murray TI, Lee W, Robinson E. The association of breast cancer and colorectal cancer in men. An analysis of the Surveillance, Epidemiology, and End Results program data. Cancer 1991;68:2069-73.

31 Eeles R, Thorlacius S, Ejfjord J, et al. The incidence of germline P53 mutations in $53 \mathrm{Li}$-Fraumeni-like families and in individuals with multiple primary tumors. $A m \mathcal{F}$ Hum Genet Suppl 1994;55:295, A55. 